\title{
Research on Effectiveness of Flipped Classroom Based on Micro Video
}

\author{
Yan Yang \\ Xi’an International University, Xi’an, 710077, China
}

Keywords: Flipped classroom, Micro video, Effectiveness of learning.

\begin{abstract}
The flexibility and convenience of micro video resources complement each other by turning the classroom interaction. The perfect combination of the two has changed the traditional teaching mode of single teaching and improved the effectiveness of teaching. This paper analyzes the internal relationship between micro video and flipped classroom, and gives the main points of micro video production in flipped classroom, which provides reference for researchers.
\end{abstract}

\section{Introduction}

Flipping class is a new way of teaching the traditional classroom. It is the traditional teaching model of classroom instruction and homework, which is turned into pre-class learning and class discussion. To realize students' learning before class, teachers must first by recording a micro video, and upload it to the network, students watch the video and micro autonomous learning. Therefore, the production of micro video has become the most important condition for the implementation of the flipped classroom teaching model. In the era of globalization and information technology, the new digital teaching technology provides a good opportunity for the reform and development of education. Miniaturization and fragmentation, and learning resources have become increasingly diversified and personalized. With the introduction of the best time for studying attention, the new curriculum reform which breaks the traditional large capacity curriculum resources has gradually become the focus. The traditional classroom teaching are two basic stages of knowledge internalization and as implementing, through the teacher lectures to impart knowledge to students by homework and practice to complete the internalization of knowledge. This traditional teaching method has a single form and cannot carry out individual guidance. Turn the mode of classroom teaching knowledge and knowledge of two stages upside down, aided by information technology, the students first before class, watch the video resources, complete the construction of knowledge, and then with the help of teachers and classmates, through collaborative learning and communication of knowledge consolidate and deepen, resulting in the process of classroom learning activities the change of teachers in the teaching, technology and video resources, has become more and more effective, more targeted. Students also become more active and cooperative in the premise of simple and quick access to learning resources.

\section{Relationship between Flipped Classroom and Micro Video}

Micro Video. The traditional network learning video is about 50 minutes long each time. It belongs to special subject study. The students in primary and middle school are tired and have difficulty concentrating and watching and studying. The effect is not ideal. While turning micro video in the classroom each approximately 10 minutes long, the small, micro and small. According to the studies on the physiology of the brain, students focus on the time is short, so the micro video dapper with students' cognitive characteristics and visual rules resides. Because of the limitation of time, each micro video can only be explained around a point of knowledge. The content is concise and the theme is prominent, which is beneficial to the improvement of students' learning efficiency. Watching traditional instructional videos, because the length is longer, students generally need to set 
aside enough time and space for viewing and learning. While watching the micro video is not many conditions, students need only a mobile phone, iPad or computer, you can at any time and any place often watch and learn, learning dapper knowledge in limited time, in line with the network era of fragmentation of information learning. The students' learning progress by its own control, watching the micro video, understand the knowledge can fast forward to skip, did not learn to understand the knowledge can be repeated viewing, even can suspend the careful thinking and make notes, the real implementation of the students according to their own learning steps. In the process of watching the micro video, there will be some small tests or advanced homework, the students only have the relevant knowledge, accurate completion of the corresponding test or advanced homework, students can continue to learn. This kind of clearance design can help students to maintain a positive learning state for a long time, consolidate the basic knowledge, avoid the knowledge point of the fault, so that students can take the initiative to absorb and internalize.

Flipped Classroom. Flip the classroom the rise in the American state of Colorado Rocky Mountain Woodland Park High School, widely welcomed by most teachers and students at home and abroad. At home, the model has also made initial progress and achieved good results. Subsequently, a pilot study was conducted. These practical researches provide valuable reference for the reform of curriculum teaching mode in our country, and lay the foundation for the implementation of the new teaching model of "flipped classroom" in our country. The basic idea is: firstly, by flipping the classroom teachers to create the teaching video, the students watch the video to explain at home or outside, and then back to the classroom for students and teachers to share and exchange between face-to-face learning achievements and experience, to achieve the goal of teaching as a form of teaching purpose. The teaching model has attracted the attention of the global educational researchers. Since its introduction to China, the influence of the "flipped classroom" has expanded rapidly. The combination of traditional classroom and online courses reflects the advantages of blended learning. Autonomous learning model is more in line with human cognitive law. The characteristic of "student oriented" has greatly changed the traditional form of Teacher centered classroom and opened a new way for building a new type of teacher-student relationship. The important role of flipping the classroom not only reverses the traditional teaching form to promote the effective use of teaching resources and development, more remodeling of teachers and students in the classroom roles, teachers to change from teaching, classroom management as a guide, facilitator and assistance, free students from passive learning in the traditional. To become a leader in autonomous learning. The content of the class is changed from the original boring and simple knowledge into interesting and independent inquiry and problem-solving learning patterns.

Integration of Flipped Classroom and Micro Video. The flipped classroom based on micro video support is not a video learning instead of a teacher's instruction. It is not a mere online class, not a student's own learning, but a blended learning. The change of the teaching method turns over the essence of the classroom, is the subversion of the traditional classroom teaching model, in class, the teacher's teaching becomes the internalization of student knowledge, the homework under the class becomes the independent watch video. Micro video, as an important part of the flipped classroom, directly determines the effect of knowledge learning before class, influences the design of classroom teaching activities, and finally affects the effect of classroom teaching. The micro video used to turn over the classroom should not be a complete classroom video, but serves as a link in the classroom or a collection of several teaching knowledge points, which are displayed on the network teaching platform. In the flipping classroom, the students watch the video, to receive the knowledge before class using a variety of mobile devices, the preliminary construction of learning content, so that teachers have more time to evaluate the students' understanding of classroom instruction, group discussion and individual learning, answering questions. Micro videos teach students basic concepts after class and promote students' Autonomous learning. In class, it can be used as a team experiment exercise. As a brief introduction to the course content, micro video can help students prepare before class, review exams, or apply practical skills. Students can master the rhythm of the watch. They understand and can skip quickly. They can either read backwards or repeatedly. Thus, teachers can guide students to study according to their own learning needs, to truly differentiate teaching. Flipping 
classes gives teachers more time to provide the fastest feedback. Teachers only need to explain the difficulties in class, excellent students can act as a teacher, to help other students problem-solving; let students flip with other outstanding students or high-level teachers, so that not only enhance the interaction between teachers and students, the interaction between students is also increased.

\section{Production Points of Micro Video in Flipped Classroom}

Video Design. Perhaps the most difficult thing for teachers is to produce high-quality video. Successful micro videos largely depend on how to integrate teaching goals with classroom activities. Do not blindly make video, you should carefully consider whether the video can produce good teaching effect. Teachers should determine whether video is a good teaching resource for students to understand and internalize knowledge according to the teaching objectives and content of the course. If the video is better than teaching to meet the teaching needs, then start planning. If it doesn't fit, then don't make videos for video, which is not good for students' learning. The choice of content depends on the teacher's accurate grasp of the difficult and difficult points of the subject knowledge. The teacher needs to determine what the students know and can do according to their professional acumen to determine the content of the video. Micro video content selection should pay more attention to the focus of teaching, difficulties, doubts; students themselves can understand, learn, must not speak. Video recording also requires a combination of discipline features. For example, mathematics has a strong logic, language and calculation process of teachers should be carried out in accordance with mathematical logic, clear, concise and to the point to promote student learning, to improve the students' autonomous learning ability and logical thinking ability. Traditional classroom instruction involves multiple goals, but the key to creating a flipped classroom video is that a video has only one theme. The quality of micro video is the key factor for students to develop autonomous learning. Therefore, the more complex content of video, the more careful design is required. The most important thing in the design is to write scripts to provide a standardized reference for video recording. Micro video scripting must collect, sort out and content related materials based on refining language, as much as possible in a limited amount of time to talk about content.

Video Recording. The teacher can record the video after he plans to record the content of the video and write the script. The teaching video has many forms, such as handwriting explanation, photograph explanation, real teaching and interview teaching. When making video, teachers often need to capture the contents of the screen, such as sound, pictures and so on. When recording videos, teachers should be able to reduce their discomfort as usual, and make the video look good and natural. In addition, the speed of interpretation should not be too fast, we should leave time for students to think. The fabrication of micro video can be combined with a variety of audio, video and other means, to fully consider the visual and auditory effects, as far as possible the interface is simple and friendly, the sound is clear, vivid, organized, pay attention to grasp and control the rhythm of the. Must use standard Mandarin, avoid to speak too quickly, enunciation is not clear, consecution is confused. The content and presentation of the micro video should be combined with the students' age characteristics and psychological characteristics, and the content and form should be combined perfectly so that the students like to watch and like listening. A good visual and audible frequency in addition to considerable, also need no noise interference or other images, even without ads, these details may affect students' learning effect. Of course, when recording micro video, you can't do it for the sake of technology. If you do not need animation, you will distract your attention. Micro video recording methods, pictures, background and text presentation, etc., should serve the students learning. First, the performance of learning in the prescribed time, such as a need for an hour to master the content, the teacher requires students to master within ten minutes is the time cannot be learned. Secondly, the performance of the appropriate starting point can be learned, teachers in the production of micro video, we should consider the characteristics of gradual progress, if there is no certain knowledge reserves and accumulation, students learn new knowledge is very difficult. At the same time, teachers should consider the diversity of students, if you make a great difference to the mandatory unified 
student learning standards and requirements, it may cause some students to learn and the other part of the students can't learn the results.

Video Machining. After the micro video recording, but also the need for processing and modification, such as removing the factors that affect students' attention; adjust the size of the sound and noise removal; increasing subtitles according to the teaching requirements; marking the key content, students can deepen the understanding; removing errors in the micro video or not perfect places for treatment and requirements the technology is more refined, the focus is on quality improvement and adjustment of micro video, to present a clear, complete picture. In this way, a teaching micro video is preliminary completed. But that's not the end of the job. A good micro video also needs to be tested by students. Teachers in the actual teaching work, can also be based on teaching results continue to be improved. But in the flipping classroom, because have learning before class, learning content has carried on the preliminary construction, so the teachers only need to explain the emphasis and difficulty in the classroom or re combing knowledge, which makes teachers have more class time to guide the students individual learning, answering questions and guide the group discussion, this interaction between students also increased. When making micro videos, the first thing a teacher should consider is what knowledge, skills, abilities, and what emotions, attitudes, and values can students learn through this micro video. This is the primary condition of education, and also the primary condition of micro video selection. Therefore, the micro video should achieve the purpose of teaching, and the theme is prominent, a micro video around a topic, or solve a knowledge point. Micro video learning just a part of classroom teaching mode, not all the teaching process, so the solution in the micro video in just a little knowledge or a theme, rather than trying to solve all the problems of the students. Similarly, teachers should not expand and deepen their knowledge, but focus on the basic knowledge that is closely related to the subject.

\section{Conclusion}

The flipped classroom based on micro video has brought a new curriculum, teaching resource and organization mode to the basic education field. It has shown a new teaching idea, teaching idea, teaching method and method. The micro video for the new digital learning environment knowledge unit as the starting point of the depth of integration of information technology and teaching, the flipped classroom based on the micro video into the curriculum teaching of basic education, has become an important index to measure the level of teaching information and content.

\section{Acknowledgement}

This paper is the result of the project of the Education Department of Shaanxi Province named "Research on Effectiveness of Flipped Classroom Based on Micro Video” (Grant No. 17JK1085).

\section{References}

[1] Xiong Jian. Flipped classroom model for the design and production of Micro-video based learning resources [J]. Journal of Southwest University for Nationalities (Natural Science Edition), 2015, 41(3): 350-355.

[2] Liu Xiaotian, Gu Daming. Empirical Research on the Flipped Classroom Teaching Based on Micro-video in Higher Vocational College [J]. Computer Engineering \& Software, 2015, 36(11): 18-22.

[3] Yang Jiumin, Shao Mingjie, Huang Lei. The Application of Flipped Classroom based on Micro-video Resources in Experimental Teaching- The Practice in Modern Educational Technology [J]. Modern Educational Technology, 2013, 23(10): 36-40.

[4] Zhao Chengling, Xu Jingjing, Liu Qingtang. The Designing and Exploring of Flipped Classroom Based on Micro-video Resources [J]. Modern Educational Technology, 2014, 24(12): 70-76. 